\title{
BMJ Open The effect of Chinese herbal medicine Jian Ling Decoction for the treatment of essential hypertension: a systematic review
}

\author{
Xingjiang Xiong, ${ }^{1}$ Pengqian Wang, ${ }^{2}$ Xiaoke $\mathrm{Li},{ }^{3}$ Yuqing Zhang ${ }^{4}$
}

To cite: Xiong $X$, Wang $P$, Li X, et al. The effect of Chinese herbal medicine Jian Ling Decoction for the treatment of essential hypertension: a systematic review. BMJ Open 2015;5 e006502. doi:10.1136/ bmjopen-2014-006502

- Prepublication history for this paper is available online. To view these files please visit the journal online (http://dx.doi.org/10.1136/ bmjopen-2014-006502).

Received 2 September 2014 Accepted 10 November 2014

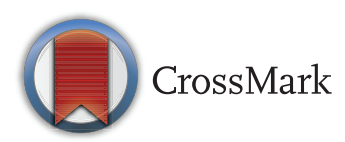

1Department of Cardiology, Guang'anmen Hospital, China Academy of Chinese Medical Sciences, Beijing, China ${ }^{2}$ Institute of Basic Research in Clinical Medicine, China Academy of Chinese Medical Sciences, Beijing, China ${ }^{3}$ Bio-organic and Natural Products Laboratory, McLean Hospital, Harvard Medical School, Belmont, Massachusetts, USA ${ }^{4}$ Department of Clinical Epidemiology and Biostatistics, McMaster University, Hamilton, Ontario, Canada

Correspondence to Dr Xingjiang Xiong; xiongxingjiangtcm@163.com

\section{ABSTRACT}

Objectives: Jian Ling Decoction (JLD) is often prescribed to improve hypertension-related symptoms in China. However, this treatment has not been systematically reviewed for its efficacy against essential hypertension (EH). This review aims to assess the current clinical evidence of JLD in the treatment of EH.

Design: Seven electronic databases, including the Cochrane Central Register of Controlled Trials, PubMed, EMBASE, the Chinese National Knowledge Infrastructure (CNKI), the Chinese Scientific Journal Database (VIP), the Chinese Biomedical Literature Database (CBM) and the Wanfang Database, were searched up to March 2014. Randomised control trials (RCTs) comparing JLD or combined with antihypertensive drugs versus antihypertensive drugs were included. We assessed the methodological quality, extracted the valid data and conducted the meta-analysis according to criteria from the Cochrane group. The primary outcome was categorical or continuous blood pressure (BP), and the secondary outcome was quality of life (QOL).

Results: Ten trials (655 patients) with unclear-to-high risk of bias were identified. Meta-analysis showed that JLD used alone showed no BP reduction effect; however, improvement on QOL was found in the JLD group compared to antihypertensive drugs. A significant reduction in systolic and diastolic BP was observed for JLD plus antihypertensive drugs when compared with antihypertensive drugs alone. No serious adverse effects were reported.

Conclusions: Owing to insufficient clinical data, it is difficult to draw a definite conclusion regarding the effectiveness and safety of JLD for EH, and better trials are needed.

\section{INTRODUCTION}

Hypertension is one of the most important preventable causes of death and one of the most common conditions treated in primary healthcare. In addition, hypertension represents an important public health challenge because of its high prevalence and the concomitant increase in the risk of cardiovascular, cerebrovascular and renal diseases. ${ }^{12}$ This condition

\section{Strengths and limitations of this study}

- The strength of this article is its use of a comprehensive and unbiased literature searching of seven electronic databases without language and publication restrictions.

- The included trials were of small sample size, with poor methodological quality and significant heterogeneity.

- No definitive conclusion regarding the efficacy and safety of JLD for EH could be drawn based on the insufficient clinical data.

has been ranked as the leading global risk factor for mortality and is the third leading risk factor for disease burden according to the comparative Risk Assessment Collaborating Group. ${ }^{3}{ }^{4}$ Currently, about one billion patients have been affected. ${ }^{5}$ The association between blood pressure (BP) and mortality was discovered approximately 100 years ago. ${ }^{6}$ Recent studies also confirmed that BP is closely related to vascular outcomes, and even a minor reduction in BP could reduce cardiovascular events, especially stroke. ${ }^{7}$ Therefore, early diagnosis and effective treatment is of great importance for patients with essential hypertension (EH). Nevertheless, despite remarkable achievements in the research and development of antihypertensive drugs, the current awareness, curative and control rates of hypertension among different age groups are still far from satisfactory. ${ }^{9} 10$ Additionally, in the light of the adverse effects of antihypertensive drugs and hoping for an adjunctive approach with few adverse effects, patients in Western countries with $\mathrm{EH}$ and other cardiovascular diseases increasingly use complementary and alternative medicine $(\mathrm{CAM}),{ }^{11-13}$ including traditional Chinese medicine (TCM). ${ }^{14-16}$

Chinese herbal medicine (CHM), one of the commonly used TCM therapies, has played an important role in relieving 
hypertension-related signs and symptoms for centuries in East Asia. ${ }^{17}{ }^{18}$ Recently, more robust evidence from systematic reviews (SRs) has suggested the efficacy and safety of CHM for EH. ${ }^{19-26}$ In TCM theory, liver yang hyperactivity syndrome (LYHS) and liver-kidney yin deficiency syndrome (LKYDS) are the two most important patterns of $\mathrm{EH}$, which often appear at the same time. ${ }^{17}$ These patterns manifest as headache, vertigo, tinnitus, irritability, insomnia, lassitude in the waist and legs, dysphoria with feverish sensation, dry mouth, bright red tongue with less fur, and a wiry pulse. ${ }^{14} 17212728$ Jian Ling Decoction (JLD) is a traditional CHM invented by Zhang Xichun in Yixue Zhongzhong Canxilu (Records of Traditional Chinese in Combination with Western Medicine) in the 1920s. It contains the following eight commonly used herbs: Dioscorea Root (Shanyao, Dioscoreae Rhizoma), Achyranthes Root (Niuxi, Achyranthis Bidentatae Radix), Hematite (Daizheshi, Haematitum), Fossilized Mammal Bones (Longgu, Os Draconis), Oyster Shell (Muli, Concha Ostreae), Rehmannia (Dihuang, Radix Rehmanniae Glutinosae), White Peony Root (Baishao, Radix Albus Paeoniae Lactiflorae) and Arbor Vitae Seed (Baiziren, Semen Platycladi). All of these herbs have been recorded in the Pharmacopoeia of the People's Republic of China (2010 edition). LYHS and LKYDS can be effectively treated with JLD. ${ }^{19}$ Currently, JLD is often prescribed for the management of EH by TCM practitioners in China. It is worth noting that in the context of CAM therapies, add-on designs are very popular for the treatment of hypertension. ${ }^{14} 20-25 \mathrm{JLD}$ is usually used in combination with antihypertensive drugs to achieve greater improvement in the signs and symptoms of hypertension and to enhance the antihypertensive effect of conventional drugs with less adverse effects. The pharmacological mechanisms of these effects may be related to the reduction in levels of angiotensin II, interleukin 6, tumour necrosis factor- $\alpha(\mathrm{TNF}-\alpha)$ and leptin, as well as insulin resistance and decreased blood lipids. ${ }^{29-34}$ Regarding the clinical use of JLD, a large number of studies (including case reports, case series, controlled observational studies and randomised trials) have reported its effects on $\mathrm{EH}$, including lowering BP, reducing inflammation, reversing cardiovascular risk factors and improving clinical symptoms and quality of life (QOL) ${ }^{35-37}$ However, there has been no comprehensive evaluation of clinical trials on the efficacy and adverse effects of JLD. This review aims to systematically review the published and unpublished randomised controlled trials (RCTs) to evaluate the current evidence for JLD in treating EH.

\section{METHODS}

This study was conducted according to the Cochrane practice. $^{38}$

\section{Search strategies}

RCTs of JLD for the treatment of patients with hypertension were screened through the following electronic databases from their respective inceptions to March 2014: Cochrane Central Register of Controlled Trials (CENTRAL, 1996-2014), PubMed (1959-2014), and EMBASE (1980-2014). In addition, as JLD is mainly prescribed in China, four Chinese electronic databases including the Chinese National Knowledge Infrastructure (CNKI, 1980-2014), Chinese Scientific Journal Database (VIP, 1989-2014), Chinese Biomedical Literature Database (CBM, 1978-2014) and Wanfang Database (1998-2014) were searched to retrieve the maximum possible number of trials. We also conducted a literature search of the website of the Chinese clinical trial registry (available at http://www.chictr.org/) and international clinical trial registry hosted by the US National Institutes of Health (available at http://clinicaltrials.gov/) for all of the relevant ongoing registered clinical trials and unpublished articles. The bibliographies of the studies identified in the systematic search were reviewed for potentially relevant additional publications. No restriction on publication status or language was imposed.

The keywords for searching databases were listed as follows: ('hypertension' OR 'essential hypertension' OR 'primary hypertension' OR 'high blood pressure' OR 'blood pressure') AND ('jian ling decoction' OR 'jianling decoction' OR 'jian ling tang' OR 'jianling tang' OR 'jianlingtang') AND ('clinical trial' OR 'randomized controlled trial' OR 'randomised controlled trial').

\section{Study selection}

\section{Types of studies}

RCTs on the use of JLD for the treatment of EH were included. Quasi-randomised trials and animal experiments were excluded.

\section{Types of participants}

Trials focused on the patients suffering from EH were included. All of the participants who were enrolled in the trials were required to meet at least one of the current or past definitions of $\mathrm{EH}^{2}{ }^{2}$ Trials without a description of the detailed diagnostic criteria but which reported patients with definite EH were also included. Patients with secondary hypertension were excluded. There was no restriction on gender, age or ethnic origin of the participants.

\section{Types of interventions}

Only studies that tested JLD used alone versus antihypertensive drugs, or JLD combined with antihypertensive drugs versus antihypertensive drugs were included. However, trials assessing the combined effect of JLD with other interventions (eg, another CHM, qigong, Tai Chi, acupuncture, moxibustion and massage) were excluded, given that the therapeutic effect of JLD could not be distinguished. Interventions in the control group included antihypertensive drugs. Studies that used nonconventional medicine or CAM as control groups were also excluded. The duration of treatment was required to be at least 2 weeks. 
According to the principle of similarity of the TCM formula, ${ }^{39}$ modified JLD should contain at least six of eight herbs used in JLD, and only a few herbs could be added into the JLD based on the TCM syndrome theory. However, the resulting prescription should contain the following four principal drugs: Achyranthes Root (Niuxi, Achyranthis Bidentatae Radix), Hematite (Daizheshi, Haematitum), Fossilized Mammal Bones (Longgu, Os Draconis) and Oyster Shell (Muli, Concha Ostreae).

\section{Types of outcome measures}

The primary outcome analysed for this meta-analysis was categorical or continuous BP, and the secondary outcome was QOL.

\section{Data extraction}

All of the articles were read by two independent reviewers. Then the eligible studies were retrieved for further identification according to the above inclusion and exclusion criteria. Duplicate papers were excluded. The data extraction form comprised the authors, title, publication year, sample size, age, sex distribution, diagnosis standard, study design, interventions in the treatment and control groups, composition of JLD or modified JLD, trial duration, outcome measures and adverse effects. If missing or unclear information regarding the original study was found, we contacted the primary authors via email, telephone or fax whenever possible. Any disagreement was resolved by discussion between the reviewers.

\section{Methodological quality}

The risk of bias of the included studies was independently evaluated by two reviewers according to the criteria in the Cochrane Handbook for Systematic Review of Interventions V.5.1.0 (updated March 2011) ${ }^{38}$ The following seven items were included: (1) sequence generation (selection bias); (2) allocation concealment (selection bias); (3) blinding of participants and personnel (performance bias); (4) blinding of outcome assessments (detection bias); (5) incomplete outcome data (attrition bias); (6) selective reporting (reporting bias); and (7) other sources of bias (from Chapter 8: assessing risk of bias in included studies).$^{38}$ Each domain was assessed as a 'high', 'unclear' or 'low' risk of bias based on the above criteria. Then the methodological quality of the trials was ranked into three levels: low risk of bias (all items with low risk of bias), high risk of bias (at least one item with high risk of bias), or unclear risk of bias (at least one item with an unclear domain).

\section{Data synthesis}

Review Manager, V.5.1 (The Nordic Cochrane Centre, Copenhagen, Denmark) was used for data analysis. The values of the outcome measures after treatment were retrieved to assess differences between the JLD and control groups. The weighted mean difference (WMD) was used for continuous data, while the risk ratio (RR) was used for binary data. Subgroups analysis was conducted among different types of comparisons (including JLD vs antihypertensive drugs and JLD plus antihypertensive drugs vs antihypertensive drugs). If high quality trials could be found, comparisons between all of the studies and studies with high quality would be conducted. In a three-group design study that had two treatment groups of JLD and JLD plus antihypertensive drugs, the two comparisons were split in the meta-analysis. Heterogeneity was assessed by $\mathrm{I}^{2}$ statistics. ${ }^{38}$ Funnel plots were applied to detect for publication bias when the number of included studies of any particular outcome was more than ten. $\mathrm{p}<0.05$ was considered to be statistically significant.

\section{RESULTS}

\section{Study characteristics}

Figure 1 shows the process of study selection. We identified 308 potentially relevant articles in the initial screening of the seven databases. Ten RCTs, with a total of 655 participants, met the eligibility criteria and were included. ${ }^{40-49}$ The basic characteristics of included trials are summarised in table 1. Six diagnostic criteria of $\mathrm{EH}$ were specified: two trials ${ }^{4041}$ used the Guidelines of Clinical Research of New Drugs of Traditional Chinese Medicine (GCRNDTCM); four trials ${ }^{42} 44 \quad 4647$ used the WHO-ISH guidelines for the management of hypertension-1999 (WHO-ISH GMH1999); one trial $^{43}$ used the WHO-ISH GMH-1985; one trial $^{45}$ used the Chinese Guidelines for the Management of Hypertension-2005 (CGMH-2005); one trial ${ }^{48}$ used the Seventh Report of the Joint National Committee on Prevention, Detection, Evaluation, and Treatment of High Blood Pressure (JNC 7); and one trial ${ }^{49}$ used the Chinese

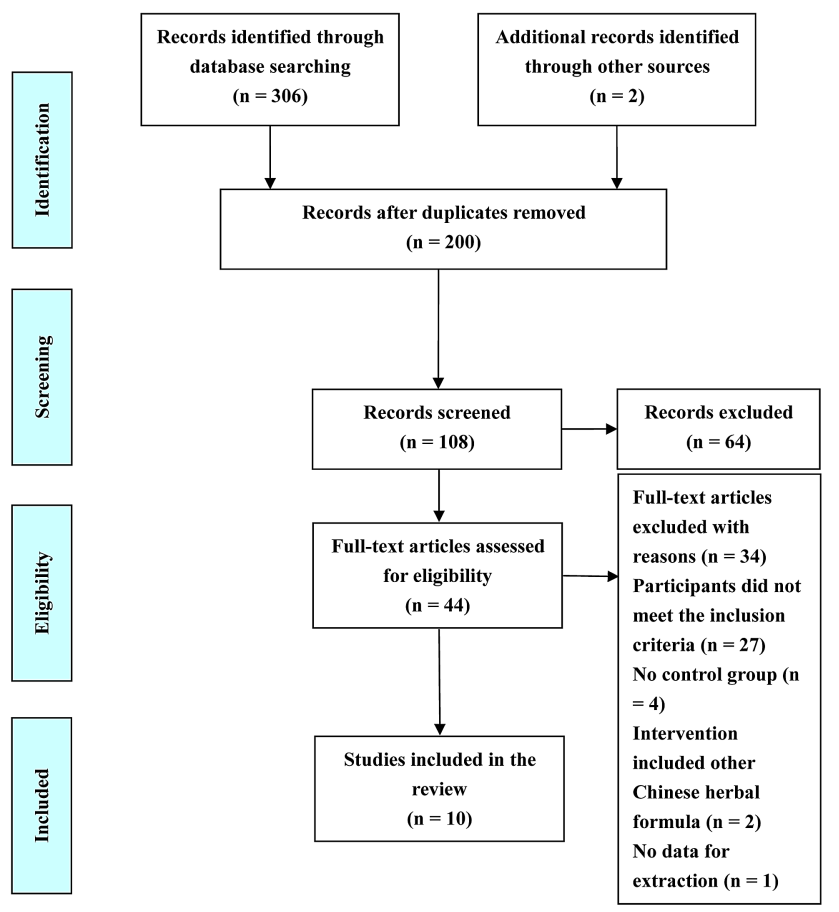

Figure 1 Flow diagram of study selection and identification. 
Table 1 Basic characteristics of the included studies

\begin{tabular}{|c|c|c|c|c|c|c|c|}
\hline Study ID & $\begin{array}{l}\text { Sample size } \\
\text { (randomised/analysed) } \\
\text { M/F }\end{array}$ & $\begin{array}{l}\text { Age } \\
\text { (years) }\end{array}$ & $\begin{array}{l}\text { Diagnosis } \\
\text { standard }\end{array}$ & Intervention & Control & $\begin{array}{l}\text { Course } \\
\text { (week) }\end{array}$ & $\begin{array}{l}\text { Outcome } \\
\text { measures }\end{array}$ \\
\hline Tong $^{40}$ & $\begin{array}{l}60 / 60 \\
\text { T: } 30 \\
\text { C: } 30 \\
\text { F/M: NR }\end{array}$ & 40-60 (T/C: NR) & GCRNDTCM & JLD (1 dose/day) & felodipine (5 mg, qd) & 4 & $\mathrm{BP}$ \\
\hline He et $a f^{11}$ & $\begin{array}{l}60 / 60 \\
\text { T: } 15 / 15 \\
\text { C: } 17 / 13\end{array}$ & $\begin{array}{l}\text { T: } 54.89 \pm 5.34 \\
\text { C: } 57.36 \pm 6.47\end{array}$ & GCRNDTCM & JLD (1 dose/day) & felodipine (5 mg, qd) & 4 & $\mathrm{BP}$ \\
\hline Fan et $a f^{42}$ & $\begin{array}{l}50 / 50 \\
\text { T: } 14 / 11 \\
\text { C: } 13 / 12\end{array}$ & $\begin{array}{l}\text { T: } 64.80 \pm 7.40 \\
\text { C: } 63.70 \pm 6.90\end{array}$ & $\begin{array}{l}\text { WHO-ISH } \\
\text { GMH-1999 }\end{array}$ & JLD (1 dose/day) & felodipine (2.5 mg, qd) & 4 & BP; QOL \\
\hline $\mathrm{Cai}^{43}$ & $\begin{array}{l}100 / 100 \\
\mathrm{~T}: 35 / 15 \\
\mathrm{C}: 34 / 16\end{array}$ & $\begin{array}{l}\text { T: } 50-81 \\
\text { C: } 47-84\end{array}$ & $\begin{array}{l}\text { WHO-ISH } \\
\text { GMH-1985 }\end{array}$ & $\begin{array}{l}\text { modified JLD (1 dose/day) } \\
\text { +control }\end{array}$ & nifedipine (10 mg, tid) & 4 & $\begin{array}{l}\text { BP; adverse } \\
\text { effect }\end{array}$ \\
\hline Zhang $^{44}$ & $\begin{array}{l}90 / 89 \\
\text { T1: } 16 / 14 \\
\text { T2: } 17 / 13 \\
\text { C: } 15 / 14\end{array}$ & $\begin{array}{l}\text { T1: } 58.23 \pm 8.26 \\
\text { T2: } 58.45 \pm 6.87 \\
\text { C: } 59.16 \pm 9.28\end{array}$ & $\begin{array}{l}\text { WHO-ISH } \\
\text { GMH-1999 }\end{array}$ & $\begin{array}{l}\text { T1: modified JLD (1 dose/day) } \\
\text { T2: modified JLD (1 dose/day) } \\
\text { +control }\end{array}$ & enalapril (10 mg, bid) & 4 & $\begin{array}{l}\text { BP; adverse } \\
\text { effect }\end{array}$ \\
\hline Zhang $^{45}$ & $\begin{array}{l}60 / 57 \\
T: 15 / 14 \\
\text { C: } 12 / 16\end{array}$ & $\begin{array}{l}\text { T: } 56.41 \pm 10.98 \\
\text { C: } 58.57 \pm 8.21\end{array}$ & CGMH-2005 & $\begin{array}{l}\text { modified JLD (1 dose/day) } \\
+ \text { control }\end{array}$ & enalapril (10 mg, bid) & 3 & $\begin{array}{l}\text { BP; adverse } \\
\text { effect }\end{array}$ \\
\hline Jiang and $\mathrm{CaO}^{46}$ & $\begin{array}{l}82 / 82 \\
\text { T: } 26 / 16 \\
\text { C: } 23 / 17\end{array}$ & $\begin{array}{l}\text { T: } 60-75 \\
\text { C: } 62-75\end{array}$ & $\begin{array}{l}\text { WHO-ISH } \\
\text { GMH-1999 }\end{array}$ & $\begin{array}{l}\text { modified JLD (100 mL/day) } \\
\text { +control }\end{array}$ & $\begin{array}{l}\text { benazepril hydrochloride } \\
(10 \mathrm{mg}, \mathrm{tid})\end{array}$ & 4 & $\mathrm{BP}$ \\
\hline Chu and $\mathrm{Xu}^{47}$ & $\begin{array}{l}67 / 67 \\
\text { T: } 19 / 15 \\
\text { C: } 17 / 16\end{array}$ & $\begin{array}{l}\text { T: } 67.00 \pm 7.20 \\
\text { C: } 68.00 \pm 5.90\end{array}$ & $\begin{array}{l}\text { WHO-ISH } \\
\text { GMH-1999 }\end{array}$ & $\begin{array}{l}\text { modified JLD (100 mL/day) } \\
+ \text { control }\end{array}$ & $\begin{array}{l}\text { nifedipine controlled release } \\
\text { tablet }(30 \mathrm{mg}, \mathrm{qd})\end{array}$ & 4 & $\mathrm{BP}$ \\
\hline Liu et $a f^{88}$ & $\begin{array}{l}60 / 60 \\
\mathrm{~T}: 30 \\
\mathrm{C}: 30 \\
\text { F/M: NR }\end{array}$ & $\begin{array}{l}18-70 \\
\text { (T/C: NR) }\end{array}$ & JNC 7 & $\begin{array}{l}\text { modified JLD (100 mL/day) } \\
\text { +control }\end{array}$ & enalapril (10 mg, bid) & 3 & $\begin{array}{l}\text { BP; adverse } \\
\text { effect }\end{array}$ \\
\hline $\mathrm{Li}^{49}$ & $\begin{array}{l}60 / 60 \\
T: 16 / 14 \\
\text { C: } 17 / 13 \\
\end{array}$ & $\begin{array}{l}\mathrm{T}: 64.33 \pm 7.96 \\
\mathrm{C}: 61.20 \pm 10.23\end{array}$ & CGMH-2010 & $\begin{array}{l}\text { modified JLD (400 mL/day) } \\
\text { +control }\end{array}$ & $\begin{array}{l}\text { nifedipine controlled release } \\
\text { tablet }(30 \mathrm{mg}, \mathrm{qd}) \text { and irbesartan } \\
(150 \mathrm{mg}, \mathrm{qd})\end{array}$ & 4 & $\begin{array}{l}\text { BP; adverse } \\
\text { effect }\end{array}$ \\
\hline
\end{tabular}


Guidelines for the Management of Hypertension-2010 (CGMH-2010). All of the studies were conducted in China and published in the Chinese language. One trial was a three-arm design (two intervention groups vs one control group), ${ }^{44}$ and the others used a two-arm study design (one intervention group vs one control group). The clinical efficacy of JLD was observed in all of the trials. However, the evaluation criteria on BP was different: three trials used the categorical BP recommended by the Chinese government in GCRNDTCM, ${ }^{40-42}$ and seven used continuous BP. $^{43-49}$ QOL was only tested in one trial. ${ }^{42}$

\section{Treatment groups}

The types of intervention were classified as JLD $(n=4)$ or combination therapy (JLD plus antihypertensive drugs, $n=7$ ). The variable prescriptions based on JLD are presented in table 1. Different compositions of either JLD or modified JLD are presented in table 2.

\section{Control groups}

All of the patients in the control groups received antihypertensive drug treatment, including felodipine, ${ }^{40-42}$ nifedipine, ${ }^{43} \quad 47 \quad 49$ enalapril $^{44} \quad 45 \quad 48$ and benazepril hydrochloride. ${ }^{46}$

\section{Treatment duration}

The total treatment duration in the trials ranged from 3 to 4 weeks, with most being 4 weeks $(n=8)$. The duration of follow-up was only mentioned in one trial, being 3 months. ${ }^{43}$

\section{Methodological quality}

As shown in table 3, four trials reported the method used to generate the allocation sequence (random number table). ${ }^{41} 444548$ Information regarding allocation concealment was provided in two trials. ${ }^{44} 48$ Blinding of participants and personnel was reported in three trials; ${ }^{44} 4548$ however, no trial used blinding of outcome assessment. Dropout and withdrawal data were provided for three trials. ${ }^{44} 4549$ No trial had a pretrial estimation of sample size. Selective reporting could not be evaluated as no preregistered protocols could be obtained from the primary authors.

\section{Outcome measures}

Primary outcome: BP

\section{JLD versus antihypertensive drugs (4 studies)}

The clinical efficacy of JLD as monotherapy for BP was assessed in four trials. ${ }^{40-42}{ }^{44}$ Three trials ${ }^{40-42}$ did not use continuous BP to evaluate the efficacy of JLD, but used categorical BP, the evaluation criteria of which have been authoritatively recommended by the China Food and Drug Administration (available at http://www.sda. gov.cn). It was defined as follows: 'significant improvement' (diastolic blood pressure (DBP) decreased by $10 \mathrm{~mm} \mathrm{Hg}$, reaching the normal range, or DBP not returning to normal but reduced by more than $20 \mathrm{~mm} \mathrm{Hg}$ ), 'improvement' (DBP decreased by less than
$10 \mathrm{~mm} \mathrm{Hg}$ but reaching the normal range, DBP decreased by $10-19 \mathrm{~mm} \mathrm{Hg}$ but not reaching the normal range, or systolic blood pressure (SBP) decreased by more than $30 \mathrm{~mm} \mathrm{Hg}$ ), and 'no improvement' (not meeting the above standards). ${ }^{50}$ These outcomes were converted into binary data for further overall analysis. Both 'significant improvement' and 'improvement' were classified as 'effective', and 'no improvement' was classified as 'ineffective'. The meta-analysis showed that JLD had no BP reduction effect compared with antihypertensive drugs $(n=170$; RR: $0.99 ; 95 \%$ CI 0.90 to $1.08 ; \mathrm{p}=0.79$; figure $2 \mathrm{~A}$ ), with no significant heterogeneity $\left(\chi^{2}=0.22, \mathrm{p}=0.90 ; \mathrm{I}^{2}=0 \%\right)$. Another trial used continuous BP to evaluate the efficacy of modified JLD when compared with enalapril. ${ }^{44}$ No significant difference was found for either SBP or DBP $(p>0.05)$.

\section{JLD plus antihypertensive drugs versus antihypertensive drugs (7 studies)}

Seven RCTs evaluated the effect of JLD combined with antihypertensive drugs versus antihypertensive drugs. ${ }^{43-49}$ Continuous BP was measured in all of these studies. SBP was significantly reduced in the JLD plus antihypertensive drugs group when compared with antihypertensive drugs ( $\mathrm{n}=485$; WMD: $-8.37 \mathrm{~mm} \mathrm{Hg} ; 95 \%$ CI -9.84 to $-6.90 ; p<0.00001$; figure $2 \mathrm{~B})$, with no significant heterogeneity $\left(\chi^{2}=8.45, \mathrm{p}=0.21 ; \mathrm{I}^{2}=29 \%\right)$. For DBP, a significant beneficial effect was also found in the JLD plus antihypertensive drugs group $(\mathrm{n}=485$; WMD: $-6.71 \mathrm{~mm} \mathrm{Hg}$; 95\% CI $-9.32,-4.10 ; \mathrm{p}<0.00001$; figure $2 \mathrm{C})$, with significant heterogeneity $\left(\chi^{2}=9.47, \mathrm{p}<0.0001\right.$; $\left.\mathrm{I}^{2}=80 \%\right)$.

\section{Secondary outcome: QOL}

Only one trial, ${ }^{42}$ conducted by Fan et $a l^{51}$, used the Croog Scale to assess the effectiveness of JLD on QOL in aged hypertension patients. At the end of the trial, QOL was significantly improved by JLD when compared with the felodipine group $(\mathrm{P}<0.05)$. The trial demonstrated that the long-term use of JLD might improve QOL for patients with hypertension.

\section{Adverse effects}

Adverse effect monitoring was reported in only five studies $^{43-45} 4849$ and was not mentioned in the other five trials. Among the former, no severe adverse effects were reported in two trials. ${ }^{43} 49$ Three trials reported dry cough caused by enalapril in the JLD and antihypertensive drug groups. ${ }^{44} 45$ Two trials reported severe dry cough in the antihypertensive drug groups. ${ }^{44}{ }^{45}$ None of the adverse effects were serious in the JLD groups.

\section{Evaluation of publication bias}

As the number of included trials was so small, it was not possible to conduct a sufficient additional analysis of publication bias. 
Table 2 Herbal medicines in the included studies

\begin{tabular}{|c|c|c|}
\hline Study ID & Formula & Composition of formula \\
\hline Tong $^{40}$ & JLD & $\begin{array}{l}\text { Arbor Vitae Seed (Baiziren, Semen Platycladi) } 10 \mathrm{~g} \text {, White Peony Root (Baishao, Radix Albus } \\
\text { Paeoniae Lactiflorae) } 10 \mathrm{~g} \text {, Rehmannia (Dihuang, Radix Rehmanniae Glutinosae) } 15 \mathrm{~g} \text {, } \\
\text { Oyster Shell (Muli, Concha Ostreae) } 10 \mathrm{~g} \text {, Fossilized Mammal Bones (Longgu, Os Draconis) } \\
10 \mathrm{~g}, \text { Hematite (Daizheshi, Haematitum) } 10 \mathrm{~g} \text {, Dioscorea Root (Shanyao, Dioscoreae } \\
\text { Rhizoma) } 15 \mathrm{~g} \text {, and Achyranthes Root (Niuxi, Achyranthis Bidentatae Radix) } 20 \mathrm{~g}\end{array}$ \\
\hline He et $a f^{41}$ & JLD & $\begin{array}{l}\text { Dioscorea Root (Shanyao, Dioscoreae Rhizoma) } 15 \mathrm{~g} \text {, Achyranthes Root (Niuxi, Achyranthis } \\
\text { Bidentatae Radix) } 20 \mathrm{~g} \text {, Hematite (Daizheshi, Haematitum) } 10 \mathrm{~g} \text {, Oyster Shell (Muli, Concha } \\
\text { Ostreae) } 10 \mathrm{~g} \text {, Fossilized Mammal Bones (Longgu, Os Draconis) } 10 \mathrm{~g} \text {, Rehmannia (Dihuang, } \\
\text { Radix Rehmanniae Glutinosae) } 15 \mathrm{~g} \text {, White Peony Root (Baishao, Radix Albus Paeoniae } \\
\text { Lactiflorae) } 10 \mathrm{~g} \text {, and Arbor Vitae Seed (Baiziren, Semen Platycladi) } 10 \mathrm{~g}\end{array}$ \\
\hline Fan et $a l^{42}$ & JLD & $\begin{array}{l}\text { Dioscorea Root (Shanyao, Dioscoreae Rhizoma) } 30 \mathrm{~g} \text {, Achyranthes Root (Niuxi, Achyranthis } \\
\text { Bidentatae Radix) } 30 \mathrm{~g} \text {, Hematite (Daizheshi, Haematitum) } 24 \mathrm{~g} \text {, Oyster Shell (Muli, Concha } \\
\text { Ostreae) } 18 \mathrm{~g} \text {, Fossilized Mammal Bones (Longgu, Os Draconis) } 18 \mathrm{~g} \text {, Rehmannia (Dihuang, } \\
\text { Radix Rehmanniae Glutinosae) } 18 \mathrm{~g} \text {, White Peony Root (Baishao, Radix Albus Paeoniae } \\
\text { Lactiflorae) } 12 \mathrm{~g} \text {, and Arbor Vitae Seed (Baiziren, Semen Platycladi) } 12 \mathrm{~g}\end{array}$ \\
\hline $\mathrm{Cai}^{43}$ & $\begin{array}{l}\text { Modified } \\
\text { JLD }\end{array}$ & $\begin{array}{l}\text { Achyranthes Root (Niuxi, Achyranthis Bidentatae Radix) } 30 \mathrm{~g} \text {, Dioscorea Root (Shanyao, } \\
\text { Dioscoreae Rhizoma) } 30 \mathrm{~g} \text {, Abalone Shell (Shijueming, Haliotidis Concha) } 30 \mathrm{~g} \text {, Hematite } \\
\text { (Daizheshi, Haematitum) } 24 \mathrm{~g} \text {, Oyster Shell (Muli, Concha Ostreae) } 18 \mathrm{~g} \text {, Fossilized Mammal } \\
\text { Bones (Longgu, Os Draconis) } 18 \mathrm{~g} \text {, Rehmannia (Dihuang, Radix Rehmanniae Glutinosae) } \\
18 \mathrm{~g} \text {, White Peony Root (Baishao, Radix Albus Paeoniae Lactiflorae) } 12 \mathrm{~g} \text {, and Arbor Vitae } \\
\text { Seed (Baiziren, Semen Platycladi) } 12 \mathrm{~g} \text {. Headache plus Puncturevine Caltrop Fruit (Cijili, } \\
\text { Tribulus terrestris Linn) } 10 \mathrm{~g} \text {; constipation plus Rhubarb Root and Rhizome (Daihuang, Radix } \\
\text { Et Rhizoma Rhei) } 5 \mathrm{~g}\end{array}$ \\
\hline Zhang $^{44}$ & $\begin{array}{l}\text { Modified } \\
\text { JLD }\end{array}$ & $\begin{array}{l}\text { Dioscorea Root (Shanyao, Dioscoreae Rhizoma) } 30 \mathrm{~g} \text {, Achyranthes Root (Niuxi, Achyranthis } \\
\text { Bidentatae Radix) } 30 \mathrm{~g} \text {, Hematite (Daizheshi, Haematitum) } 24 \mathrm{~g} \text {, Oyster Shell (Muli, Concha } \\
\text { Ostreae) } 18 \mathrm{~g} \text {, Fossilized Mammal Bones (Longgu, Os Draconis) } 18 \mathrm{~g} \text {, Rehmannia (Dihuang, } \\
\text { Radix Rehmanniae Glutinosae) } 18 \mathrm{~g} \text {, White Peony Root (Baishao, Radix Albus Paeoniae } \\
\text { Lactiflorae) } 12 \mathrm{~g} \text {, and Arbor Vitae Seed (Baiziren, Semen Platycladi) } 12 \mathrm{~g} \text {. Headache, } \\
\text { dizziness, and irritability plus Gastrodia (Tianma, Gastrodiae Rhizoma) } 15 \mathrm{~g} \text { and Abalone } \\
\text { Shell (Shijueming, Haliotidis Concha) } 30 \mathrm{~g} \text {; irritability, bitty mouth and red face plus Coptis } \\
\text { Rhizome (Huanglian, Rhizoma Coptidis) } 10 \mathrm{~g} \text { and Gardenia (Zhizi, Fructus Gardeniae } \\
\text { Jasminoidis) } 10 \mathrm{~g} \text {; and constipation plus Rhubarb Root and Rhizome (Daihuang, Radix Et } \\
\text { Rhizoma Rhei) } 5 \mathrm{~g}\end{array}$ \\
\hline Zhang $^{45}$ & $\begin{array}{l}\text { Modified } \\
\text { JLD }\end{array}$ & $\begin{array}{l}\text { Dioscorea Root (Shanyao, Dioscoreae Rhizoma) } 30 \mathrm{~g} \text {, Achyranthes Root (Niuxi, Achyranthis } \\
\text { Bidentatae Radix) } 30 \mathrm{~g} \text {, Hematite (Daizheshi, Haematitum) } 24 \mathrm{~g} \text {, Oyster Shell (Muli, Concha } \\
\text { Ostreae) } 18 \mathrm{~g} \text {, Fossilized Mammal Bones (Longgu, Os Draconis) } 18 \mathrm{~g} \text {, Rehmannia (Dihuang, } \\
\text { Radix Rehmanniae Glutinosae) } 18 \mathrm{~g} \text {, White Peony Root (Baishao, Radix Albus Paeoniae } \\
\text { Lactiflorae) } 12 \mathrm{~g} \text {, and Arbor Vitae Seed (Baiziren, Semen Platycladi) } 12 \mathrm{~g} \text {. Excessive } \\
\text { accumulation of phlegm-dampness plus Pinellia Rhizome (Banxia, Rhizoma Pinelliae } \\
\text { Tematae) } 15 \mathrm{~g} \text {, Sclerotium of Tuckahoe (Fuling, Scierotium Poriae Cocos) } 15 \mathrm{~g} \text {, Tangerine } \\
\text { Peel (Chenpi, Pericarpium Citri Reticulatae) } 10 \mathrm{~g} \text {, Bamboo Shavings (Zhuru, Bambusae } \\
\text { Caulis in Taeniam) } 10 \mathrm{~g} \text {, and Liquoric Root (Gancao, Radix Glycyrrhizae) } 3 \mathrm{~g}\end{array}$ \\
\hline Jiang and $\mathrm{Cao}^{46}$ & $\begin{array}{l}\text { Modified } \\
\text { JLD }\end{array}$ & $\begin{array}{l}\text { Dioscorea Root (Shanyao, Dioscoreae Rhizoma) } 30 \mathrm{~g} \text {, Fresh Water Turtle Shell (Guijia, } \\
\text { Plastrum Testudinis) } 30 \mathrm{~g} \text {, Achyranthes Root (Niuxi, Achyranthis Bidentatae Radix) } 30 \mathrm{~g} \text {, } \\
\text { Hematite (Daizheshi, Haematitum) } 20 \mathrm{~g} \text {, Oyster Shell (Muli, Concha Ostreae) } 20 \mathrm{~g}, \\
\text { Fossilized Mammal Bones (Longgu, Os Draconis) } 20 \mathrm{~g} \text {, Rehmannia (Dihuang, Radix } \\
\text { Rehmanniae Glutinosae) } 20 \mathrm{~g} \text {, White Peony Root (Baishao, Radix Albus Paeoniae } \\
\text { Lactiflorae) } 15 \mathrm{~g} \text {, and Arbor Vitae Seed (Baiziren, Semen Platycladi) } 15 \mathrm{~g}\end{array}$ \\
\hline Chu and $X u^{47}$ & $\begin{array}{l}\text { Modified } \\
\text { JLD }\end{array}$ & $\begin{array}{l}\text { Rehmannia (Dihuang, Radix Rehmanniae Glutinosae) } 25 \mathrm{~g} \text {, Fresh Water Turtle Shell (Guijia, } \\
\text { Plastrum Testudinis) } 25 \mathrm{~g} \text {, Dioscorea Root (Shanyao, Dioscoreae Rhizoma) } 30 \mathrm{~g} \text {, Hematite } \\
\text { (Daizheshi, Haematitum) } 15 \mathrm{~g} \text {, Oyster Shell (Muli, Concha Ostreae) } 25 \mathrm{~g} \text {, Fossilized Mammal } \\
\text { Bones (Longgu, Os Draconis) } 25 \mathrm{~g} \text {, Achyranthes Root (Niuxi, Achyranthis Bidentatae Radix) } \\
25 \mathrm{~g} \text {, White Peony Root (Baishao, Radix Albus Paeoniae Lactiflorae) } 20 \mathrm{~g} \text {, and Arbor Vitae } \\
\text { Seed (Baiziren, Semen Platycladi) } 20 \mathrm{~g}\end{array}$ \\
\hline Liu et $a f^{48}$ & $\begin{array}{l}\text { Modified } \\
\text { JLD }\end{array}$ & $\begin{array}{l}\text { Dioscorea Root (Shanyao, Dioscoreae Rhizoma) } 30 \mathrm{~g} \text {, Rehmannia (Dihuang, Radix } \\
\text { Rehmanniae Glutinosae) } 18 \mathrm{~g} \text {, Hematite (Daizheshi, Haematitum) } 24 \mathrm{~g} \text {, Oyster Shell (Muli, } \\
\text { Concha Ostreae) } 18 \mathrm{~g} \text {, Fossilized Mammal Bones (Longgu, Os Draconis) } 18 \mathrm{~g} \text {, Achyranthes } \\
\text { Root (Niuxi, Achyranthis Bidentatae Radix) } 30 \mathrm{~g} \text {, White Peony Root (Baishao, Radix Albus }\end{array}$ \\
\hline
\end{tabular}


Table 2 Continued

\begin{tabular}{|c|c|c|}
\hline Study ID & Formula & Composition of formula \\
\hline $\mathrm{Li}^{49}$ & $\begin{array}{l}\text { Modified } \\
\text { JLD }\end{array}$ & $\begin{array}{l}\text { Paeoniae Lactiflorae) } 20 \mathrm{~g} \text {, and Arbor Vitae Seed (Baiziren, Semen Platycladi) } 20 \mathrm{~g} . \\
\text { Excessive accumulation of phlegm-dampness plus Pinellia Rhizome (Banxia, Rhizoma } \\
\text { Pinelliae Tematae) } 15 \mathrm{~g} \text {, Sclerotium of Tuckahoe (Fuling, Scierotium Poriae Cocos) } 15 \mathrm{~g} \text {, } \\
\text { Tangerine Peel (Chenpi, Pericarpium Citri Reticulatae) } 10 \mathrm{~g} \text {, Bamboo Shavings (Zhuru, } \\
\text { Bambusae Caulis in Taeniam) } 10 \mathrm{~g} \text {, and Liquoric Root (Gancao, Radix Glycyrrhizae) } 3 \mathrm{~g} \\
\text { Fossilized Mammal Bones (Longgu, Os Draconis) } 30 \mathrm{~g} \text {, Oyster Shell (Muli, Concha Ostreae) } \\
30 \mathrm{~g} \text {, Rehmannia (Dihuang, Radix Rehmanniae Glutinosae) } 20 \mathrm{~g} \text {, Hematite (Daizheshi, } \\
\text { Haematitum) } 20 \mathrm{~g} \text {, Dioscorea Root (Shanyao, Dioscoreae Rhizoma) } 30 \mathrm{~g} \text {, Achyranthes Root } \\
\text { (Niuxi, Achyranthis Bidentatae Radix) } 30 \mathrm{~g} \text {, White Peony Root (Baishao, Radix Albus } \\
\text { Paeoniae Lactiflorae) } 20 \mathrm{~g} \text {, Arbor Vitae Seed (Baiziren, Semen Platycladi) } 15 \mathrm{~g} \text {, Gambir Vine } \\
\text { Stems and Thorns (Gouteng, Ramulus Uncariae Cum Uncis) } 30 \mathrm{~g} \text {, Pueraria (Gegen, Radix } \\
\text { Puerariae) } 30 \mathrm{~g} \text {, Gastrodia (Tianma, Gastrodiae Rhizoma) } 15 \mathrm{~g} \text {, Chinese Taxillus Twig } \\
\text { (Sangjisheng, Herba Taxilli) } 30 \mathrm{~g} \text {, Eucommia Bark (Duzhong, Cortex Eucommiae Ulmoidis) } \\
15 \mathrm{~g} \text {, and Coptis Rhizome (Huanglian, Rhizoma Coptidis) } 9 \mathrm{~g}\end{array}$ \\
\hline
\end{tabular}

\section{DISCUSSION}

\section{Summary of evidence}

Taking into account the gap between the lack of scientific evidence regarding the efficacy of JLD and the widespread application by TCM practitioners, the objective of this study was to systematically review the current English and Chinese literature to evaluate the efficacy and safety of JLD for EH. To the best of our knowledge, this is the first SR of JLD in English.

Ten claimed RCTs, with a total of 655 patients with hypertension, met the inclusion criteria and were included in this review. The results suggested that SBP and DBP were significantly improved in patients receiving JLD plus antihypertensive drugs therapy, although the effect was not significant in the JLD alone group. Moreover, JLD was found to be effective in terms of improving QOL when compared with antihypertensive drugs. However, the evidence for JLD as an effective modality for treating $\mathrm{EH}$ was restricted by a limited

Table 3 Methodological quality of included studies based on the Cochrane handbook

\begin{tabular}{|c|c|c|c|c|c|c|c|}
\hline Included trials & $\mathbf{A}$ & B & C & D & $\mathbf{E}$ & $\mathbf{F}$ & G \\
\hline Tong $^{40}$ & $?$ & $?$ & $?$ & $?$ & + & ? & $?$ \\
\hline He et $a f^{41}$ & + & $?$ & $?$ & $?$ & + & $?$ & ? \\
\hline Fan et $a l^{42}$ & $?$ & $?$ & $?$ & $?$ & + & ? & $?$ \\
\hline $\mathrm{Cai}^{43}$ & $?$ & + & $?$ & $?$ & + & ? & ? \\
\hline Zhang $^{44}$ & + & + & + & $?$ & + & ? & $?$ \\
\hline Zhang $^{45}$ & + & $?$ & + & $?$ & + & ? & ? \\
\hline Jiang and $\mathrm{Cao}^{46}$ & $?$ & $?$ & $?$ & $?$ & + & ? & $?$ \\
\hline Chu and $X u^{47}$ & $?$ & $?$ & $?$ & $?$ & + & ? & $?$ \\
\hline Liu et al ${ }^{48}$ & + & + & + & $?$ & + & $?$ & $?$ \\
\hline $\mathrm{Li}^{49}$ & $?$ & $?$ & $?$ & $?$ & + & $?$ & $?$ \\
\hline
\end{tabular}

A, adequate sequence generation; $\mathrm{B}$, concealment of allocation; $\mathrm{C}$, blinding (participants and personnel); D, blinding (assessor); $\mathrm{E}$, incomplete outcome data addressed (ITT analysis); $F$, free of selective reporting; $\mathrm{G}$, other potential threat to validity; +, low risk; -, high risk; ?, unclear. number of trials, small sample sizes, poor methodological quality and a high risk of bias in primary studies.

\section{Limitations}

The following limitations should be considered before accepting the findings of this review.

1. Although there were two randomised, single-blind, controlled trials, the methodology of most of the included trials was assessed to be generally poor. The main reasons are analysed as follows:

First, although all studies claimed randomisation, only four trials demonstrated the random sequence generation, and two trials reported allocation concealment; therefore, selection bias may exist. Second, only three trials described the blinding of participants and personnel; however, no trials reported the blinding of outcome assessment. Therefore, both selection bias and detection bias might have occurred. Third, only three trials reported dropout or withdrawal statistics, suggesting a high risk of attrition bias. Fourth, most of the included studies did not mention the intention-to-treat analysis, which may lead to some other bias. Fifth, no trials had a pre-estimation of sample size. Sixth, no trial had a placebo control, which might decrease the quality of positive conclusions.

2. As shown in figure $2 \mathrm{C}$, heterogeneity is another critical issue that should be considered, which may be associated with variations in study quality, participants, JLD compositions and antihypertensive drugs.

3. The limited number of included trials and different interventions in the JLD and antihypertensive drug groups restricted us from conducting meaningful subgroup analyses to explore effect modifiers such as the duration of intervention and types of antihypertensive drug therapies.

4. Publication bias should also be considered. In this review, all of the included trials were conducted in China and published in Chinese. Almost all studies 


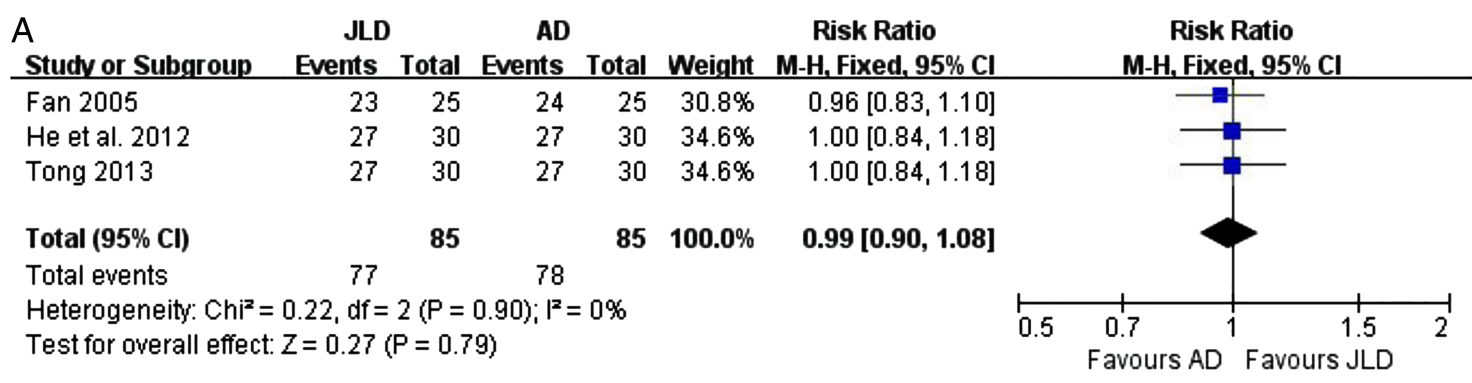

Figure 2 (A) Effect of Jian Ling Decoction (JLD) on blood pressure (BP). (B) JLD versus AD (systolic blood pressure (SBP) $\mathrm{mm}$ $\mathrm{Hg}$ ) and (C) JPAD versus $A D$ (diastolic blood pressure (DBP) $\mathrm{mm} \mathrm{Hg}$ ). AD, antihypertensive drugs; JPAD, Jian Ling Decoction plus antihypertensive drugs.

claimed a similar beneficial effect or a better effect when compared with antihypertensive drugs alone. No negative conclusions were found. What is more, a funnel plot checking for possible publication bias for BP could not be conducted due to the small number of included studies.

5. Although one trial had a short-term follow-up, most of the studies had no follow-up, indicating a lack of knowledge for some critical outcomes, such as allcause mortality and progression to severe complications due to high $\mathrm{BP}$, which is the most common problem for TCM studies in general.

6. As the use of natural products is very common among patients in a variety of healthcare settings, the safety of CHM and potential herb-drug interactions has hence become a concern. This review suggested that JLD may be safe for the management of EH. In fact, no parallel double blind randomised placebo controlled trials indicating the adverse effects of JLD for EH could be found. Owing to the insufficient clinical data, it is difficult to draw a definitive conclusion regarding the safety of JLD for $\mathrm{EH}$ at present. We therefore suggest that the adverse effects of JLD need to be monitored rigorously in future studies.

\section{CONCLUSION}

Owing to the insufficient clinical data, poor methodological design and high risk of bias, it is difficult to draw a definite conclusion regarding the effectiveness and safety of JLD for EH. More rigorously designed trials reported according to the CONSORT statement are needed. ${ }^{52-54}$

Acknowledgements The author would like to thank Cheryl $C$ from American Journal Experts (AJE) for revising the English language of the manuscript.

Contributors XX conceived the idea for the study and designed the method of this systematic review and meta-analysis including the inclusion and exclusion criteria. XX also performed data collection and extraction, conducted the statistical analysis and wrote the first draft of the article. PW, $X L$ and $Y Z$ searched the articles and assessed their methodological quality. Disagreement was resolved by discussion between $\mathrm{XX}, \mathrm{PW}, \mathrm{XL}$ and $\mathrm{YZ}$. PW performed the 
major revision, interpreted the results and made comments. All of the authors approved the final version of the manuscript.

Funding XJX was supported by the National Natural Science Foundation Project of China (No. 81403375).

Competing interests None.

Provenance and peer review Not commissioned; externally peer reviewed.

Data sharing statement Extra data can be accessed via the Dryad data repository at http://datadryad.org/ with the doi:10.5061/dryad.8rc01.

Open Access This is an Open Access article distributed in accordance with the Creative Commons Attribution Non Commercial (CC BY-NC 4.0) license, which permits others to distribute, remix, adapt, build upon this work noncommercially, and license their derivative works on different terms, provided the original work is properly cited and the use is non-commercial. See: http:// creativecommons.org/licenses/by-nc/4.0/

\section{REFERENCES}

1. Lawes CM, Hoorn SV, Rodgers A; For the International Society of Hypertension. Global burden of blood-pressure-related disease 2001. Lancet 2008;371:1513-18.

2. James PA, Oparil S, Carter BL, et al. 2014 Evidence-based guideline for the management of high blood pressure in adults report from the panel members appointed to the Eighth Joint National Committee (JNC 8). J Am Med Assoc 2014;311:507-20.

3. Ezzati M, Lopez AD, Rodgers A, et al. Comparative risk assessment collaborative group: selected major risk factors and global and regional burden of disease. Lancet 2002;360:1347-60.

4. Kearney PM, Whelton M, Reynolds K, et al. Global burden of hypertension: analysis of worldwide data. Lancet 2005;365:217-23.

5. Lopez AD, Mathers CD, Ezzati M, et al. Global and regional burden of disease and risk factors 2001: systematic analysis of population health data. Lancet 2006;367:1747-57.

6. Fisher JW. The diagnostic value of the sphygmomanometer in examinations for life insurance. J Am Med Assoc 1914;63:1752-4.

7. Lewington S, Clarke R, Qizilbash N, et al. Prospective Studies Collaboration. Age-specific relevance of usual blood pressure to vascular mortality: a meta-analysis of individual data for one mil-lion adults in 61 prospective studies. Lancet 2002;360:1903-13.

8. Law MR, Morris JK, Wald NJ. Use of blood pressure lowering drugs in the prevention of cardiovascular disease: meta-analysis of 147 randomised trials in the context of expectations from prospective epidemiological studies. Brit Med J 2009;338:b1665, 1-19.

9. Xiong XJ, Yang XC, Liu YM, et al. Chinese herbal formulas for treating hypertension in traditional Chinese medicine: perspective of modern science. Hypertens Res 2013;36:570-9.

10. Chow CK, Teo KK, Rangarajan S, et al. Prevalence, awareness, treatment, and control of hypertension in rural and urban communities in high-, middle-, and low-income countries. J Am Med Assoc 2013;310:1-10.

11. Brook RD, Appel LJ, Rubenfire M, et al. Beyond medications and diet: alternative approaches to lowering blood pressure. Hypertension 2013;61:1360-83.

12. Mansoor GA. Herbs and alternative therapies in the hypertension clinic. Am J Hypertens 2001;14:971-5.

13. Xiong XJ, Borrelli F, Ferreira AS, et al. Herbal medicines for cardiovascular diseases. Evid Based Complement Alternat Med 2014;2014:e809741, 1-3.

14. Wang J, Xiong XJ. Current situation and perspectives of clinical study in integrative medicine in China. Evid Based Complement Alternat Med 2012;2012:e268542, 1-11.

15. Wang J, Feng B, Yang XC, et al. Chinese herbal medicine for the treatment of prehypertension. Evid Based Complement Alternat Med 2013;2013:e493521, 1-9.

16. Tachjian A, Maria V, Jahangir A. Use of herbal products and potential interactions in patients with cardiovascular diseases. J Am Coll Cardiol 2010;55:515-25.

17. Xiong XJ, Yang XC, Liu W, et al. Trends in the treatment of hypertension from the perspective of traditional Chinese medicine. Evid Based Complement Alternat Med 2013;2013:e275279, 1-13.

18. Wang J, Xiong XJ. Control strategy on hypertension in Chinese medicine. Evid Based Complement Alternat Med 2012;2012. e284847, 1-6.

19. Wang J, Xiong XJ. Evidence-based Chinese Medicine for Hypertension. Evid Based Complement Alternat Med 2013;2013: e978398, 1-12.
20. Wang J, Xiong XJ. Outcome measures of Chinese herbal medicine for hypertension: an overview of systematic reviews. Evid Based Complement Alternat Med 2012;2012:e697237, 1-10.

21. Wang J, Feng B, Yang XC, et al. Tianma gouteng yin as adjunctive treatment for essential hypertension: a systematic review of randomized controlled trials. Evid Based Complement Alternat Med 2013;2013:e706125, 1-18.

22. Xiong $\mathrm{XJ}$, Yang $\mathrm{XC}$, Feng $\mathrm{B}$, et al. Zhen gan xi feng decoction, a traditional Chinese herbal formula, for the treatment of essential hypertension: a systematic review of randomized controlled trials. Evid Based Complement Alternat Med 2013;2013:e982380, 1-9.

23. Wang J, Yang XC, Feng B, et al. Is Yangxue Qingnao Granule combined with antihypertensive drugs, a new integrative medicine therapy, more effective than antihypertensive therapy alone in treating essential hypertension?. Evid Based Complement Alternat Med 2013;2013:e540613, 1-8.

24. Xiong XJ, Liu W, Yang XC, et al. Ginkgo biloba extract for essential hypertension: a systemic review. Phytomedicine 2014;21:1131-6.

25. Wang J, Yao KW, Yang XC, et al. Chinese patent medicine liu wei di huang wan combined with antihypertensive drugs, a new integrative medicine therapy, for the treatment of essential hypertension: a systematic review of randomized controlled trials. Evid Based Complement Alternat Med 2012;2012:e714805, 1-7.

26. Wang J, Feng B, Xiong XJ. Chinese herbal medicine for the treatment of obesity-related hypertension. Evid Based Complement Alternat Med 2013;2013:e757540, 1-11.

27. Lu AP, Jia HW, Xiao C, et al. Theory of traditional Chinese medicine and therapeutic method of diseases. World J Gastroenterol 2004;10:1854-6.

28. Jiang WY. Therapeutic wisdom in traditional Chinese medicine: a perspective from modern science. Trends Pharmacol Sci 2005;26:558-63.

29. Ge HX, Dai XM, Zhang ZX, et al. Modern application and experimental research progress of jian ling decoction. Acta Chin Med Pharm 2002;30:21-3.

30. Yu HW. Effect of modified jian ling decoction on insulin resistance and serum levels of TNF- $\alpha$ in patients with essential hypertension. Haerbin: Heilongjiang Univ Chin Med 2008;1-56.

31. Cao JM. Effect of modified jian ling decoction on serum leptin and angiotensin II in hypertension with insulin resistance. Haerbin: Heilongjiang Univ Chin Med 2012;1-51.

32. Jiang CX. Effect of modified jian ling decoction on blood pressure and angiotensin II in elderly hypertensive patients. Haerbin: Heilongjiang Univ Chin Med 2012;1-51.

33. Zhang N, Sun JL, Dong ZZ, et al. Effect of modified jian ling decoction on insulin resistance and serum interleukin- 6 of essential hypertension patients. Chin $\mathrm{J}$ Inform Tradit Chin Med 2011;18:19-21.

34. Feng DR, Wei B. Effects of jian ling decoction on the blood lipid and lipid peroxidationin in experimental hyperlipidemia rats with yin deficiency of liver and kidney. Guangxi J Tradit Chin Med 2009;32:51-4.

35. Huang YT, Wu CB, Zeng QM. Effect of jian ling decoction on 120 patients of essential hypertension. Chin J Integr Tradit West Med 1996;16:561.

36. Hao HY, Wang QH, Sun CJ, et al. Effect of modified jian ling decoction on 30 patients of essential hypertension. Shanxi J Tradit Chin Med 1998;19:541.

37. Guan DM, Du SQ. Clinical observation on the effect of jian ling decoction combined with urapidil on stage III hypertension with high-risk. Chin Commun Doct 2013;15:214-15.

38. Higgins JPT, Green S. Cochrane Handbook for Systematic Reviews of Interventions, Version 5.1.0. The Cochrane Collaboration. 2011. http://handbook.cochrane.org/

39. Li YB, Cui M, Yang Y, et al. Similarity of traditional Chinese medicine formula. Chin Arch Tradit Chin Med 2012;30:1096-7.

40. Tong $\mathrm{WH}$. Analysis on clinical therapeutic effect of jian ling decoction on essential hypertension with yin deficiency and yang hyperactivity syndrome. Guide China Med 2013;11:258-9.

41. He T, Zhu YQ, Xu SX. Effect of jian ling decoction on 30 hypertensive patients with yin deficiency and yang hyperactivity syndrome. Guid J Tradit Chin Med Pharm 2012;18:50-1.

42. Fan R, Zhou H, Tan HY. Effect of jian ling decoction on aged hypertension patient's life mass and CAT. China J Mod Med 2005;15:1706-8.

43. Cai XP. Combined traditional Chinese and western medicine in the treatment of 50 patients with essential hypertension. Guagndong Med J 1995;16:400-2.

44. Zhang N. Effect of modified jian ling decoction on essential hypertension. Haerbin: Heilongjiang Univ Chin Med 2004;1-34. 
45. Zhang N. Effect of modified jian ling decoction on insulin resistance and serum levels of IL-6 in essential hypertension. Haerbin: Heilongjiang Univ Chin Med 2009;1-51.

46. Jiang CX, Cao JM. Effect of modified jian ling decoction on renin-angiotensin II in patients with senile hypertension. Chin J Tradit Med Sci Technol 2012;19:145.

47. Chu GM, Xu JY. Effect of modified jian ling decoction on high-sensitivity C-reactive protein on 67 cases of hypertensive patients. J Inform Tradit Chin Med 2013;30:66-7.

48. Liu L, Jin J, Yu HW. Effect of modified jian ling decoction on insulin resistance and TNF- $\alpha$ level in patients of EH. J Inform Tradit Chin Med 2008;25:68-70, 80.

49. $\mathrm{Li} \mathrm{CM}$. Effect of modified jian ling decoction on senile primary hypertension. Jinan: Shandong Univ Chin Med 2013;1-30.
50. Xiong XJ, Liu W, Yang XC, et al. Moxibustion for essential hypertension. Complement Ther Med 2014;22:187-95.

51. Croog SH, Levine S, Testa MA, et al. The effect of antihypertensive therapy on the quality of life. N Engl J Med 1986;314:1657-9.

52. Liu JP, Han M, Li XX, et al. Prospective registration, bias risk and outcome-reporting bias in randomised clinical trials of traditional Chinese medicine: an empirical methodological study. BMJ Open 2013;3:e002968, 1-7.

53. Schulz KF, Altman DG, Moher D. CONSORT 2010 statement: updated guidelines for reporting parallel group randomized trials. Ann Intern Med 2012;152:726-32.

54. Gagnier JJ, Boon $\mathrm{H}$, Rochon $\mathrm{P}$, et al. Reporting randomized, controlled trials of herbal interventions: an elaborated CONSORT statement. Ann Intern Med 2006;144:364-7. 